\title{
análise comparativa das políticas de combate ao mosaico da cana-de-açúcar em são paulo e em minas gerais*
}

\author{
Graciela de Souza Oliver \\ Bolsista PRODOC-CAPES, Programa de Pós-Graduaçào em História da Universidade Federal de \\ Minas Gerais
}

RESUMO

Neste artigo, apresento uma análise comparativa das políticas de combate à doença do mosaico da cana-de-açúcar paulista e mineira, das décadas de 1920 e 1930. Primeiramente, inicio com o contexto histórico e econômico das duas agroindústrias canavieiras. Depois, caracterizo o modelo internacional de difusão de uma nova tecnologia agrícola, no caso, as variedades de cana javanesas, bem como suas fases e suas conseqüências para o desenvolvimento do setor. Em seguida, comparo as políticas em relação ao contexto institucional das ciências agrícolas nas duas regiões. O objetivo desse artigo é mostrar que a inserção da nova tecnologia esteve relacionada ao processo de institucionalização das ciências agrícolas, conferindo também particularidades regionais ao processo de modernizaçãotecnológica.

Palavras-chave: história da tecnologia história da institucionalização das ciências agrícolas - história da política científica e tecnológica - história da agroindústria canavieira - Brasil

\section{ABSTRACT}

On this paper I present a comparative analysis between the policies of the Sao Paulo State and the Minas Gerais State related to the mosaic sugarcane, a plant disease that toke place on the 1920's and 1930 's. First I give the historical and economical context of the two sugarcane industries. Second I show the model of international diffusion of sugarcane agrarian technologies, its periods and consequences to the economic development of the sector. In the end, I compare those politics in face of the regional institutional context of the agricultural sciences. The objective of this paper is to show that the insertion of the new technologies was related to the institutionalization of agricultural science process, conferring regional particularities to the technological process of modernization.

Keywords: history of technology - agricultural sciences institution - science and technological policy - history - history of sugarcane industries - Brazil

* Submetido: outubro, 2007; aceito: abril, 2008. 


\section{Aspectos gerais da evolução da agroindústria canavieira paulista e mineira no início do século XX}

A segunda metade do século XIX é vista pela historiografia como uma fase de definição do projeto político da nação e do início da construção do próprio Estado. A partir desse momento e depois da Proclamação da República (1889), diversas frações das elites agrárias puderam manifestar seus interesses, visando permanecer no poder (MENDONÇA, 1990). A transformação dos engenhos de cana-de-açúcar em engenhos centrais foi um desses projetos, beneficiando principalmente a Região Nordeste.

Entretanto, a separação entre a produção agrícola e a produção industrial não vingou nos moldes iniciais previstos, como explica Eisenberg (1977). E, na seqüência, foram fundadas usinas, amparadas por grandes subsídios do Governo Imperial, com o objetivo de recuperar o mercado internacional. Mesmo assim, a produção das usinas e dos pequenos engenhos foi sendo paulatinamente destinada cada vez mais aos mercados dos centros urbanos e em crescimento do sudeste (SZMRECSÁNYI, 1988).

A partir do início do século XX, e em virtude do crescimento constante dessa demanda, nota-se também o crescimento da produção de açúcar no sudeste, competindo com o açúcar nordestino antes mes mo da década de 1930 (Idem, 1988, 1992). Conforme apresentaram Ramos \& Szmrecsányi (2002), destaco alguns elementos históricos e constitutivos do crescimento da agroindústria canavieira paulista, a partir de fins do século XIX: 1) crescimento da lavoura canavieira em consórcio e amparada pelos excedentes da produção do café; 2) forma $\neg$ ção de um grupo de quatro usinas, líderes no mercado, sendo todas elas de propriedade da Société des Sucreries Brésiliennes, de capital estrangeiᄀ ro;3) aumento crescente e contínuo da demanda interna por açúcar em São Paulo; 4) aumento dos preços do açúcar, da aguardente e do álcool no mercado vis a vis as flutuações e as quedas dos preços do café; 5) superação da crise do mosaico;6) diversificação e ampliação da ca pacidade produtiva, em especial c o m a reversão das destilarias de álcool em usinas, a partir da década de 1940.

Em Minas Gerais, a cultura da cana-de-açúcar foi uma atividade colonial como nas demais províncias, precedendo o café (CARRARA, 
1999:44). Contudo, ainda no século XIX, sua característica distintiva foi o estabelecimento de um grande número de engenhos, um número maior do que em Pernambuco, bem como por sua produção ter sido destinada ao consumo interno, fugindo ao modelo agrário exportador (GODOY, 2004:95; 2007:12).

No decorrer do século XIX, as atividades mineiras de produção e comercialização do açúcar, da rapadura e da aguardente desenvolveramse voltadas para o abastecimento tanto dos mercados locais como do interior do nordeste, em menor medida. Inexistia a especialização pro $\neg$ dutiva e os excedentes da produção eram preponderantemente vendidos nas cercanias (Idem, 2004:109). Grosso modo, a produção concentravase na região central de Minas Gerais, pautada na mão-de-obra escrava, existindo uma correlação entre o tamanho da população escrava e o número de engenhos (Ibidem, pp. 105, 535).

Vale ressaltar que a região da Zona da Mata não apresentava produ $\neg$ ção destacada na terceira década do século XIX. Segundo Carrara (1999:22), "Quando o recenseamento de 1872 foi feito, apurou-se que a Mata - cuja área correspondia a cerca de 5\% do território da Província - detinha $16,57 \%$ da população total e $24,39 \%$ da população escrava de Minas Gerais". No início do século XIX, seguindo seu padrão histórico de desenvolvimento (Ibidem, p. 105), algumas cidades da Zona da Mata, como Ponte Nova, Visconde do Rio Branco, Além Paraíba e Viçosa, destacaram-se por uma produção variada (café, milho, feijão e fumo) e por uma considerável produção de açúcar e aguardente (CAR RAR A, 1999:62).

Foi nessas cidades citadas e também em Ubá que surgiram as priᄀ meiras usinas de açúcar. Paralelamente a essa produção, figurava também a dos engenhos de açúcar, cujo número suplantava o de qualquer outra região de Minas Gerais no ano-safra de 1922/25 (GODOY, 2004:106). Assim, na lenta substituição do trabalho escravo pelo livre, se São Paulo optou pelo colonato imigrante, em Minas Gerais o trabalhador nacional foi reintegrado à produção de açúcar pelo sistema de parceria (SHIKIDA \& B ACHA, 1997:17), dando uma sobrevida ao padrão da lavoura cana vieira de Minas Gerais por boa parte do século XX.

Contudo, a partir da segunda metade do século XX, seria crescente o número de usinas, em detrimento dos engenhos nas regiões da Zona da Mata, do Campo das Vertentes, da Central Mineira, da Metropolita- 
na de Belo Horizonte, do Oeste de Minas, do Sul/Sudoeste de Minas e do Triângulo Mineiro/Alto do Parnaíba (GODOY, 2007:18). Entendese que parte desse relativo progresso da agroindústria canavieira minei $\neg$ ra foi motivado também pelas políticas do Instituto do Açúcar e do Álcool (IAA, 1933), sem que estas viessem a consolidar a atividade como um forte segmento da economia estadual, levando também em consi deração a produção dos engenhos (SHIKIDA \& B ACHA, 1998:65).

Em face dos traços históricos gerais e comuns às duas lavouras canavieiras, ao menos até a primeira metade do século XX, noto duas per manências. De um ângulo, está a manutenção dessa atividade, ao longo do século XIX, em locais que se tornaram pequenos núcleos urbanos ou estavam próximos. Neles, o açúcar tornou-se um gênero alimentício de primeira necessidade (RAMOS \& SZMRECSÁNYI, 2002:88) e/ou esteve vinculado às economias locais, quer fosse a escravista, quer a do café. De outro, vê-se a correspondência entre a concentração fundiária e o estabelecimento de uma produção moderna (EISENBERG, 1977; GRAZIANO DA SILVA, 1980; RAMOS, 1999).

Com exceção dessas poucas semelhanças gerais, Shikida (1992) e Shikida \& Bacha (1997) levantaram os aspectos diferenciadores entre a agroindústria canavieira mineira e a paulista, na passagem do século XIX para o XX. Para esses autores, Minas Gerais saiu em desvantagem em relação à produção paulista, porque: 1) a produção cafeeira mineira apresentava menor dinamismo, demonstrando, inclusive, uma preferên $\neg$ cia pela aplicação dos excedentes na produção pecuária; 2) a produção de açúcar bruto e de rapadura era realizada por um grande número de pequenos engenhos e distribuída no mercado local; 3) havia um grande número de empreendedores isolados e com pouca influência política; 4) as redes de viação eram deficientes; 5) não foi criada uma infra-es $\neg$ trutura técnica de longo prazo face à crise do mosaico; 6) quando da criação do Instituto do Açúcar e do Álcool (IAA), não se nota a formaᄀ ção de um grupo forte que fizesse frente aos interesses nacionais, incor $\neg$ porado àquele órgão de regulamentação da produção de açúcar.

Conseqüentemente, Minas Gerais teria passado a importar açúcar do nordeste, embora tenha existido um crescimento contínuo do nú mero de usinas, de sua produção e de seus rendimentos (SHIKIDA, 1992). Essa situação foi possível em virtude do aumento da demanda pelo produto e do constante decréscimo do número de unidades e do volu- 
me da produção dos engenhos, no decorrer do século XX. Em contra partida, São Paulo teria, ao lado do aumento da produção e da capaci $\neg$ dade das usinas, o aumento da produção dos engenhos, especialmente depois de 1940. Pôde, assim, suprir suas necessidades internas, passando então a exportar açúcar a partir da década de 1950.

Para Godoy (2007:12), Minas Gerais, Goiás e Ceará são representa tivos de um tipo de processo de modernização comparativamente mais lento e/ou tardio, mantendo número expressivo de engenhos por maior tempo. E, c o mo também salientou Szmrecsányi (1988:50), para o período posterior à criação do IAA, a fixação de quotas de produção teria des $\neg$ motivado a obtenção de maiores índices de produtividade ou de níveis de custo mais baixos, uma vez que os preços fixos garantiram aos pe $\neg$ quenos engenhos uma rentabilidade mínima.

Dentre o conjunto de fatores econômicos e políticos, a ausência de uma infra-estrutura científico-tecnológica em face da crise do mosaico foi destacada como diferenciador entre São Paulo e Minas Gerais. Em estudo recente, fiz uma análise das políticas paulistas de debelação do mosaico, sendo estas consideradas como ponto de início e fundamentais para um processo de modernização tecnológica em São Paulo, desde que tomadas em conjunto com os demais elementos contextuais pre sentes (VEIGA FILHO \& SANTOS, 1995; QUEDA, 1998; OLIVER, 2001; RAMOS \& SZMRECSÁNYI, 2002). Entretanto, é possível afirmar que a incorporação continuada de tecnologia agrícola em um determinado momento foi crucial para que essa dinâmica tivesse seguimento em novas bases (OLIVER \& SZMRECS ÁNYI, 2003).

Para Shikida (1992:79) e Shikida \& Bacha (1997:25):

A diferença dessas políticas reside no fato de São Paulo ter criado um aparato de pesquisa que se preocupou com a agroindústria canavieira sob uma ótica de longo prazo (mais desenvolvimentista). A política mineira, apesar de bem sucedida a curto prazo, visava apenas a geração de mudas que atendessem às demandas domésticas (...).

Seguindo o raciocínio dos autores, podemos questionar se teria ocorrido apenas uma diferença entre uma política efêmera e outra de longo prazo, ou, então, se esta política de longo prazo gerou por si mes $\neg$ ma uma influência nacional, ao passo que o atendimento imediato es $\neg$ taria fadado ao esmorecimento no tempo e no espaço. 
Por outro lado, essas questões desconhecem que o aporte das ciᄀ ências e das tecnologias teve também a sua história, apresentando li gações históricas muito específicas em cada sociedade. Na historiografia atual das ciências e da tecnologia, nota-se um esforço em contextualizar, criticar e revisar os modelos gerais de difusão da ciên cia e da tecnologia para os países que foram ex-colônias, superando a visão dicotômica entre internalismo e externalismo (LAFUENTE \& ORTEGA, 1998; SALDANA, 2000). E mesmo que a historiografia em geral já tenha ultrapassado o recorte regional para o período repu $\neg$ blicano (VISCARDI, 2005:338), acredito que ainda seja válido um esforço de análise comparativa, realçando as semelhanças e as diferen ças dos apoios dados às atividades de ciência e tecnologia no Brasil, na Primeira República.

Um debate como esse nos levaria a dialogar diretamente com os modelos de difusão internacional de tecnologia agrícola, sem conside $\neg$ rar as especificidades da "periferia" como fases atrasadas. Desse modo, amparada por um estudo recente sobre a institucionalização das ciências agrícolas (OLIVER, 2005, e OLIVER \& FIGUEIRÔA, 2006), pergunto quais elementos institucionais foram específicos para o aporte da nova variedade de cana-de-açúcar em São Paulo e Minas Gerais. Dessa ma $\neg$ neira, penso ser possível fazer uma nova avaliação comparativa entre as políticas de debelação do mosaico.

É importante ressaltar que os dados para Minas Gerais foram levan tados concomitantemente a outras pesquisas, cujo foco não era essa te mática particular. Estudos futuros poderão aprofundar a análise dos dados históricos aqui apresentados. Tal aprofundamento necessariamen $\neg$ te deverá passar pelo entendimento geral do papel da ciência e da tec $\neg$ nologia na sociedade e no Estado de Minas Gerais, do levantamento sistemático de documentação das próprias usinas, dos diversificados relatórios acadêmicos da Escola Superior de Agricultura de Viçosa e das publicações agrícolas diversas, que não foram contempladas em sua totalidade pela presente autora.

Desse modo, este artigo restringe-se a apresentar as etapas e as ca racterísticas gerais do processo internacional de difusão de uma nova tecnologia no mundo canavieiro. Em seguida, descreve as políticas con $\neg$ tra o mosaico em São Paulo e em Minas Gerais, cada qual em seu contexto institucional de aporte das ciências agrícolas e, por fim, com- 
para os diferentes contextos de inserção da nova tecnologia agrícola e suas possíveis conseqüências em relação ao processo de modernização.

\section{Variedades de canas como tecnologias e seu processo de difusão no mundo}

Antes do século XIX, o incremento da produção canavieira através de novas variedades dependia da observação e do reconhecimento da manifestação aleatória das mesmas na natureza. N o final do século XVIII, c om o crescimento das cidades européias, o consumo do açúcar elevouse, exigindo modificações na organização industrial, originando as centrais açucareiras e demandando modificações técnicas, por exemplo, pela introdução da máquina a vapor. Data também dessa época a insta $\neg$ lação das primeiras unidades produtivas do açúcar de beterraba, aumen tando o volume de açúcar comercializado e diminuindo seus preços, através de uma crescente concorrência no mercado internacional (B YE et at., 1993:40 e 42).

Em virtude dessas modificações, da concorrência com o açúcar de beterraba e do aperfeiçoamento técnico da produção de açúcar de cana, as variedades de cana nobre (Saccharum officinarum) que apresentassem melhores características industriais (como o teor de sacarose e a maior produtividade agrícola) foram rapidamente difundidas no mundo canavieiro, no decorrer do século X I X. Por esses motivos, variedades oriun das de diferentes países ou regiões entraram na "moda", tais como a Bourbon, a Otaheit, a Louzier (Preta), a Cristalina e a Rosa.

Essas mesmas variedades de canas nobres também chegaram aos canaviais brasileiros no início do século X X, sendo, porém, utilizadas com maior freqüência nos canaviais de São Paulo e do Rio de Janeiro. Vieram substituir as variedades Creoula e Caiana, que dominavam as plantações de cana-de-açúcar no Brasil e no mundo.

Segundo Evenson (1974:60), a transferência dessas canas representou um primeiro estágio de difusão de tecnologia. A tecnologia, nesse caso, pode ser entendida como o domínio sobre os conhecimentos científi cos da época, relativos ao desenvolvimento da planta em cada condição agrícola de produção, para a obtenção e a manutenção das característi $\neg$ cas vegetativas já conhecidas e/ou desejadas industrialmente. Concomitantemente ao trânsito desses conhecimentos, ocorria também o de uma 
série de doenças, as quais podiam ser conhecidas ou desconhecidas, mas eram antes restritas às regiões de origem.

Nesse contexto também de mudança técnica, em virtude da con $\neg$ corrência entre os países canavieiros, na busca por variedades próprias ao uso industrial, e pela difusão de doenças como a gomose e o mosai co, entre 1890 e 1925, alguns pesquisadores buscaram desenvolver novas formas de produção de mudas de cana.

Até meados do século XIX, acreditava-se que as inflorescências da cana-de-açúcar não fossem férteis, sendo suas mudas obtidas através da reprodução vegetativa, por estacas. Ao proceder dessa forma, os planta dores de cana deixavam de obter características industriais desejáveis e observadas em diversas variedades ou em exceções naturais.

A partir de fins do século XIX, as recém-criadas estações experimentais de Java e de Barbados descobriram cientificamente como se processava a fertilização da cana-de-açúcar, possibilitando o cruzamen $\neg$ to sexual entre as diferentes variedades. Como estas regiões eram pos $\neg$ sessões coloniais de países europeus, maciços investimentos deram início a programas de melhoramento de canas nobres. Estas variedades foram posteriormente transferidas a outros países canavieiros, repre sentando um segundo estágio de difusão de tecnologia. Contudo, tais variedades continuavam sendo suscetíveis a doenças, be m como à per da de seus atributos no decorrer do tempo.

Na década de 1910, a Proefstation Oost Java passou a fazer cruzamentos interespecíficos de canas nobres (Saccharum officinarum) e canas selvagens (Saccharum spontaneum). De tais cruzamentos obtiveram a variedade POJ 2878, cuja finalidade era criar uma cana resistente às doenças e com altos rendimentos (EVENSON, 1976:212). Dez anos depois, va riedades de cana-de-açúcar como aquelas foram disseminadas, repre sentando um terceiro estágio do processo de difusão de tecnologia.

Outras variedades de cana-de-açúcar, c om a identificação POJ, foram difundidas largamente pelo mundo canavieiro junto com as variedades indianas - as CO (Coimbatore Experimental Station), durante as décadas de 1930 e 1940. As variedades indianas eram o resultado de uma série de três cruzamentos (S. officinarum $x$ S. spontaneum $x$ S. barberi). Além de resistentes às doenças, essas variedades foram criadas visando a uma melhor adaptação local ao clima e ao solo (EVENSON, 1976:213), re presentando um quarto estágio de difusão de tecnologia. 
A importância das variedades javanesas, a partir do terceiro estágio, e das indianas, para o desenvolvimento de uma rede de pesquisa cien tífica e tecnológica internacional, se deve ao fato de que elas traziam em si características muito específicas. Continham conhecimentos de genética, de fitopatologia, de pedologia, de climatologia, de fisiologia, etc. Por essa especificidade, os países e as regiões que mais detinham esses conhecimentos - como a Índia, Java, o Havaí, Cuba e Barbados e os Estados Unidos - intensificaram o intercâmbio de informações com outros países sobre a criação e a adaptação de variedades às condições locais (Idem, 1974:59). A partir desse estágio, para incorporar as novas variedades desenvolvidas, era necessário ter uma organização científica capaz de reconhecer as características e testá-las, observando se estas eram mantidas no tempo, da mesma forma que na região de origem.

Em muitos países, como no caso do Brasil, já existiam estações ex $\neg$ perimentais desde fins do século XIX, como as de Barreiros (PE) e de Campos (RJ). A criação dessas estações experimentais, entre outras razões, também pode estar relacionada ao processo internacional de difusão de variedades ou de tecnologia.

No caso da Estação de Barreiros, seu surgimento se deu possivelᄀ mente relacionado à difusão das canas nobres e ao surto de gomose no final do século XIX. Já a criação da Estação de Campos parece estar ligada ao resultado das atividades pioneiras de cruzamento entre canas nobres de Java e Barbados, bem como pela difusão das mesmas. Entre tanto, ambas as instituições passaram por constantes reformulações, sendo incorporadas a outros organismos e, por vezes, perdendo suas finalidades iniciais, recuperando-as num momento seguinte.

Também se observa que, no início do século X X, houve um esforço também intermitente do Instituto Agronômico de Campinas (SP) na adaptação de canas nobres, que eram próprias para os tipos de solos e climas de duas regiões açucareiras de São Paulo (OLIVER, 2001:43-44). Contudo, as principais contribuições dessas três instituições, até a década de 1920, ficaram restritas à recomendação de variedades nobres (prin cipalmente as de Barbados), que eram adaptadas para o cultivo regional, ao invés da criação de variedades locais, por meio da repetição de cru zamentos já efetuados ou da realização de novos.

$\mathrm{O}$ aporte desse conhecimento sobre fecundação das canas no Brasil dependia da existência de especialistas, de investimentos em infra-estrutura 
de pesquisa e assistência técnica e da constituição de uma demanda política e econômica pelos proprietários de usinas e engenhos de cana-de-açúcar, ou mesmo do próprio Estado. Deste modo, segundo Evenson (1974:59), a partir do cruzamento entre diferentes espécies de cana-de-açúcar, distinguiram-se os centros que faziam as principais descobertas científicas e os demais, que desempenhavam um papel secundário ou adaptativo no processo geral de difusão internacional de tecnologia. Entretanto, mesmo exercendo um papel de adaptador das tecnologias, esses locais também construíram novos conhecimentos sobre as variedades, integrando-se àquela rede internacional em deter $\neg$ minados momentos.

A Estação Experimental de Tucumã, na Argentina, criada em 1909, também fez parte desse processo de constituição de uma rede internaᄀ cional de difusão de tecnologia agrícola em cana-de-açúcar. Em meados da década de 1910, executavam-se cruzamentos e se aclimatavam canas nobres em Tucumã. Mas, com a irrupção do mosaico a partir de 1915, teve também que importar as canas POJ 36 e POJ 213 (CROSS, 1929:1). Estas variedades eram resultantes do cruzamento entre canas nobres e foram caracterizadas como resistentes ao mosaico, mas sem apresentar boas características industriais em Java (VIZIOLI, 1927:49).

Ao importá-las, os pesquisadores da Estação de Tucumã observaram, em testes de produtividade agrícola e industrial, seu ótimo desempenho em face das baixas temperaturas e das geadas, além de sua resistência ao mosaico. Após a debelação da doença, a pesquisa da estação tucumana voltou-se para a pesquisa genética, visando criar variedades argentinas regionais, além de proceder à constante importação de variedades dos centros de vanguarda.

Este foi também o caso da Estação Experimental de Canal Point, na Lousiana (EUA). Em 1918, julgando ser o mosaico uma doença fisiológica, apontou como medida profilática o corte dos canaviais, ao invés da substituição de variedades (SECRETARIA DA A GRICULTURA INDÚS TRIA E COMÉR CIO, São Paulo, 1931:39). Co mo esta medida não obteve sucesso, incorporou também as variedades javanesas e investiu em programas de melhoramento para criar variedades regionais norteamericanas. Em conseqüência, nos anos entre 1940 e 1960, constava como um dos principais centros de melhoramento genético em cana (EVENSON, 1976:219). 
Nesse caso, podemos dizer que os conhecimentos de aclimatação foram fundamentais para que os centros de pesquisa pudessem, com o passar do tempo, incorporar as novas tecnologias, que envolvessem a criação e a adaptação de variedades geneticamente melhoradas por meio de cruzamento. De forma geral, nota-se que as doenças, em especial o mosaico, se apresentaram como elementos de integração dos centros de pesquisa a uma rede de difusão de tecnologia, cujo modelo institucional era o de estação experimental. Outra conse $\neg$ qüência desse processo de incorporação de tecnologia na produção canavieira foi o aumento da produção de açúcar. Já na década de 1960, vários dos países que criaram centros dessa natureza apresentaram um aumento da produção de açúcar e dos índices de açúcar por tonelada de cana, inclusive o Brasil, conforme cita Evenson (1976:221).

\section{Institucionalização das ciências agrícolas e as políticas contra o mosaico em São Paulo e em Minas Gerais}

No ano de 1924, tanto o Instituto Agronômico como a Secretaria da Agricultura do Estado de São Paulo, através da Comissão de Debelação da Praga Cafeeira, estavam trabalhando no combate da broca do café e da praga do algodão, iniciativas que resultaram, em 1925, na cria $\neg$ ção do Instituto Biológico de Defesa Agrícola (SILVA, 2006). Exceto pela atuação esparsa dessas instituições e das atividades técnicas da $\mathrm{Se} \neg$ cretaria de Agricultura, não havia um aparato institucional para os problemas específicos da cana-de-açúcar. Assim, entre 1924 e 1926, as atividades de debelação do mosaico ficaram basicamente centralizadas na pessoa de José Vizioli.

Esse agrônomo havia identificado, em 1923, canas doentes nos canaviais da Escola Superior de Agricultura "Luiz de Queiroz" (ESALQ 1901), onde atuava como professor-assistente contratado. Em um artigo publicado pela Secretaria da Agricultura, recomendou aos lavradores de cana algumas medidas provisórias de controle do mosaico.

Mesmo sem ter identificado o que apenas na década de 1950 se entenderia como um vírus, José Vizioli tinha os conhecimentos cientí ficos para prescrever medidas de tratamento dos canaviais. As medidas eram as seguintes: 1) "semente doente produz canas doentes", devendo-se, 
portanto escolher as canas para o plantio antes do corte das pontas; 2) os agricultores não deverão desanimar e poderão remediar o mal, esco lhendo, para sementes, as canas menos atacadas; 3) mesmo assim, pode haver infestações secundárias. O agricultor deverá inspecionar periodi $\neg$ camente seus canaviais e arrancar toda e qualquer planta que apresentar sintomas seguros ou suspeitos do mosaico; 4) não cultivar milho nas proximidades ou deixar o crescimento de outros matos e gramíneas. O estado de limpeza das culturas concorre grandemente para a redução dos insetos veiculadores de moléstias da cana-de-açúcar; 5) o mosaico é moléstia incurável das plantas e não das plantações. Nenhum microbicida e nenhum inseticida têm efeitos sobre a desinfecção das semen $\neg$ tes de cana, como também a moléstia não infecciona o solo e nenhum adubo pode influir na planta, no sentido de curar-lhe a doença; 6) a queima dos canaviais não é aconselhável para combater pragas e molés $\neg$ tias difundidas em uma região (VIZIOLI, 1924:6-9).

Foi a partir dessa publicação que o poder público passou a ter inte resse pelas atividades de José Vizioli. Até aquela data, contava somente com o apoio da ESALQ, através do laboratório de Fitopatologia de Averna Saccá, seu ex-professor, e com o apoio de jornais importantes, que se interessavam pelos assuntos relativos à ciência, como O Estado de S. Paulo, para que assim explicitasse a natureza da crise.

É importante destacar que nesse momento a imprensa diária tinha o interesse na ciência em um duplo viés. Do ponto de vista do proces $\neg$ so de institucionalização das ciências, desde fins do século XIX ao início do XX, os jornais serviam como um local de visibilidade para os cientistas e para as ações científicas do Estado (FIGUEIRÔA \& LOPES, 1997). De um outro, relativo ao processo de legitimação mais amplo da ciência e da tecnologia na sociedade, os meios de comunicação passaram a atuar no campo da divulgação científica, principalmente a partir da década de 1920, criando uma demanda específica por notícias científicas (MASSARANI \& MOREIRA, 2000). Neste processo de construção de uma esfera pública da ciência moderna, o rádio, a imprensa diária e alguns periódicos especializados construiriam um papel para a ciência e a tecnologia na sociedade brasileira.

Pela circulação das notícias e cientes da doença em São Paulo, os produtores pernambucanos iniciaram a construção de novas instalações e o alargamento do plantio de cana. Os dados da produção da época 
mostravam o constante declínio entre os anos-safras de 1922/23 e 1924/1925 (OLIVER, 2001:21). Além da crise, eram motivados pelo aumento dos preços do açúcar e pela demanda não atendida do merca $\neg$ do paulista, apostando que a produção paulista não se reergueria.

Essa conjuntura foi mais um fato que pressionou a Secretaria da Agricultura do Estado de São Paulo no auxílio aos produtores de cana e de açúcar. Comojá indiquei anteriormente, não havia uma instituição central de assistência técnica, ou fitopatológica, que atendesse às con $\neg$ sultas dos agricultores em geral e sobre outras culturas além do café. Nesse momento, tal atendimento estava disperso na atuação dos inspe tores agrícolas da Secretaria de Agricultura do Estado de São Paulo, do Instituto Agronômico de Campinas e de alguns professores da ESALQ, de acordo com sua especialidade.

É importante lembrar que a noção de assistência técnica, tal como conhecemos atualmente, ainda não existia. E, apesar de em constante mudança até início da década de 1930, a noção de fomento agrícola exe $\neg$ cutada em São Paulo fundamentava-se nos seguintes pilares: recolhimen to de dados estatísticos da produção e da instrução agrícola. O espaço para essas atividades se dava na imprensa de divulgação agrícola em constante profusão a partir de 1910, nos campos de demonstração e por consultas dos particulares aos centros reconhecidos como da ciência agrícola.

No ano de 1925, José Vizioli publicou vários artigos co m o grifo da Diretoria de Publicidade. A partir dessas notas ou minutas, publicadas por aquela diretoria, buscava-se criar um elo entre o Estado e os agri cultores. Paralelamente, o Instituto Agronômico de Campinas tomou a iniciativa de importar canas da Argentina, mas estas foram retidas na repartição dos Correios (SECRETARIA DA A GRICULTURA INDÚS TRIA E COMÉRCIO, 1926:53). Não há uma indicação explícita sobre quem teria proposto essa medida, salientando-se apenas o receio de que a doença se alastrasse para fora de São Paulo.

Compreende-se que, em sendo o referido instituto uma entidade de alcance nacional, a medida buscava privilegiar outros atores, be m como outros modos de proceder perante a crise. Na seqüência, em dezembro de 1925, por determinação do Ministério da Agricultura, Artur Neiva reorientou algumas pessoas que trabalhavam na defesa contra a broca do café para o mosaico da cana-de-açúcar em São Paulo (Folha da Ma nhã, 10/12/1925). 
Tais medidas deram exclusividade e um meio formal de atuação para José Vizioli que, na seqüência, foi contratado como fitopatologista da campanha da broca do café. A exclusividade também se deu na medida em que ele era reconhecido para identificar não somente as melhores canas estrangeiras, como vinha procedendo o Instituto Agronômico de Campinas, mas aquelas que poderiam obter sucesso em Piracicaba, maior região produtora da época.

Assim, ele foi encarregado de criar definitivamente um Serviço de Defesa da Cana, como também de importar pessoalmente as variedades da Estação Experimental de Cana-de-açúcar de Tucumã, na Argentina. Eram essas canas, no seu entendimento de especialista, que serviriam para a debelação do mosaico em São Paulo. Segundo José Vizioli, quan do se procedeu à "inspeção em diversos municípios, verificou-se afinal a existência, num recanto de Ribeirão Preto, de quatro variedades javanesas que, crescendo em completa promiscuidade, apresentavam certa resistência à moléstia" (O Estado de S. Paulo, 07/09/1933).

Foi c o m base naquelas variedades que José Vizioli importou diversos tipos de variedades javanesas e indianas, preconizando as seguintes va $\neg$ riedades: POJ 213, POJ 36, POJ 228 e POJ 234. Faço notar que todas faziam parte do segundo estágio internacional de difusão. Na verdade, ele tratou tão somente de ampliar a disseminação das variedades que os usineiros já haviam trazido anteriormente da Argentina para São Paulo.

Depois de importadas, o serviço de substituição das variedades co meçou com a quarentena dessas mudas no quintal da casa de José Vizioli, em Piracicaba, sendo transplantadas numa área da ESALQ e, então, distribuídas (SECRETARIA DA AGRICULTURA, INDÚSTRIA E COMÉRCIO, 1927:33). Co m essas medidas, foram desencadeados dois processos decisivos e até certo ponto tardios - o de substituição das variedades e o da idealização e posterior concretização da Estação Experimental de Piracicaba, já preconizada por José Vizioli num artigo seu, de 1926 (OLIVER \& SZMRECSÁNYI, 2003). Co mo início da substituição, a produção de açúcar elevou-se de 226.639 sacas, em 1924/25, para $451.480 \mathrm{em}$ $1925 / 26$, e alcançou 742.170 sacas de $60 \mathrm{~kg}$ no ano safra de 1926/27 (OLIVER, 2001:21 e 60). A partir desse ano, José Vizioli receberia cada vez maior apoio da Secretaria da Agricultura do Estado de São Paulo e de outros pesquisadores, tais como Rosario Averna Saccá e Agesilau A. Bitancourt, do Instituto Biológico, que endossavam sua proposta. 
Com essa recuperação paulista e com a expansão do mosaico nos canaviais brasileiros (BITT ANCOURT, 1926:22) foram instaurados uma comissão nacional contra o mosaico, um concurso e um prêmio para trabalhos que revelassem a etiologia do mosaico. Contudo, tais discussões não tiveram implicações técnicas, pois, a essa época, José Vizioli já estava ocupado no plano de Defesa da Cana, tanto pelo Estado de São Paulo como pelo Governo Federal (ESTADO DE PERNAMBUCO, 1927).

Para o caso mineiro, Shikida (1992) afirma que as medidas de debelação do mosaico ficaram a cargo da Secretaria de Agricultura do Estado de Minas Gerais a partir de 1928. Nela foram promovidas ações para a disseminação das variedades javanesas provenientes de São Paulo e também diretamente da Argentina. O autor ainda observa que foram criados campos de estudo em Ponte Nova, Rio Branco, Cataguazes e Passos, além de outros serviços especiais no Campo de Sementes de Nova Baden e Carmo da Mata.

Esses foram os esforços que o autor compreendeu como imediatistas e de menor custo, quando, de fato, foram idênticos aos esforços iniciais paulistas e coerentes com o plano nacional de debelação. Vale lembrar que a campanha de substituição oficial paulista havia começado dois anos antes da mineira, em 1926. Entretanto, foi em São Paulo que o mosaico irrompeu primeiro. Assim, enquanto em São Paulo as variedades javanesas representavam 90\%dos canaviais, no ano de 1932, Minas Gerais estava no meio do processo de substituição, assim como os demais Estados da federação que haviam aderido ao plano nacional de defesa da cana, posteriormente.

Paralelamente, um processo de institucionalização das ciências agrín colas vinha ocorrendo desde, no mínimo, meados do século XIX. A partir desse momento final de emergência dos conhecimentos da agricultura científica e do estabelecimento dos tipos institucionais necessá rios para o aporte e o desenvolvimento dessa área, as escolas superiores de agricultura foram privilegiadas, ao invés dos institutos e das estações experimentais (OLIVER \& FIGUEIRÔA, 2006).

O Instituto Agronômico de Campinas e o Instituto Biológico cons $\neg$ tituíram-se em exceções no cenário nacional. Ao final da década de 1920, o Instituto Agronômico criou sua primeira Estação Experimental regional, localizada em Tietê, a partir de um antigo campo de demons $\neg$ tração. Tinha como finalidade debelar uma praga e experimentar varie- 
dades de algodão, selecionando-as e distribuindo-as (ALBUQUERQUE et al., 1986).

A criação e a manutenção de centros de pesquisa e experimentação dessa natureza dependiam tanto da formação de agrônomos e especia listas, em determinado ramo das ciências agrícolas ou cultura, como de um conhecimento agronômico geral sobre as condições agrícolas re gionais dos Estados. Contribuíram para tanto a atuação da ESALQ, que formava agrônomos desde 1901 (Mendonça, 1998:91), mantendo-se como a principal escola brasileira até a década de 1950 (Oliver, 2005:27 e 149), a Comissão Geográfica e Geológica Paulista, cujo primeiro mapa com referências agrícolas data de 1908 (Figueirôa, 1997:204), e o Insti tuto Agronômico de Campinas, que realizava pesquisas agronômicas desde 1887 (Meloni, 1999).

Apesar de ainda pouco estudado em seu conjunto, podemos dizer que o processo de institucionalização das ciências agrícolas em Minas Gerais seguiu traços comuns ao país, mas apresentou especificidades. Em relação ao levantamento das zonas agrícolas, a Comissão Geográfica e Geológica de Minas Gerais apresentou seu primeiro mapa em 1893, mas a avaliação das terras agrícolas foi delegada a outras instituições (GOMES, 2005:173). Assim, priorizaram o levantamento topográfico da região sul e central de Minas Gerais e, posteriormente, os interesses dessa comissão voltaram-se para o estabelecimento dos limites com o Estado de São Paulo e do Rio de Janeiro, até a década de 1930. Conseqüentemente, segundo a autora acima citada, todo o projeto de integração mineiro ainda estava por ser feito, inclusive em termos de vias de comunicação, que, iniciadas em fins do século XIX, tiveram continuidade somente a partir da década de 1920.

Na seqüência, ao final do século XIX, o governo mineiro tentou implementar sem sucesso Institutos Agrícolas e de Zootecnia, com a dupla finalidade de realizar pesquisas agronômicas e manter cursos para filhos de fazendeiros. O insucesso tem sido atribuído às contingências políticas e à falta de público. Com a entrada do mineiro Affonso Pena na Presidência da República e a adesão do Presidente de Minas Gerais - Silviano Brandão - com a política de cortes orçamentários, tanto a Comissão Geográfica e Geológica de Minas Gerais como os Institutos Agronômicos e Zootécnicos e as Colônias Agrícolas para a Zona da Mata foram deixadas de lado. 
Segundo Gorceix (1897), o ensino prático, ou seja, aquele pautado pela demonstração da agricultura científica, não atraía os filhos de faᄀ zendeiros, porque estes ainda tinham preconceito com o trabalho ma nual, mesmo que científico. Segundo Viscardi (1995:49), este teria sido um momento em que as elites do sul, aliadas às do centro, romperam com as da Zona da Mata, o que possivelmente teria fragilizado a inserção da proposta de um grupo de reformistas naquela região. Desde fins do século XIX, este grupo via na modernização e na civilização da agricultura uma saída para Minas Gerais (RIBEIRO, 2000).

Assim, a partir desse momento, tanto no centro como no sul de Minas Gerais, as iniciativas de ensino agrícola em geral foram man tidas, tanto por capitais privados como, depois, federais. Surgiram, então, escolas particulares do ensino agrícola superior, como em Lavras (1908), no sul de minas, e em Belo Horizonte (1914), na nova capital do estado, cuja orientação também primava pela experimen $\neg$ tação científica. Ainda por iniciativa particular, foi criada a Escola Superior de Agricultura de Passa Quatro (1918), na região sul, e a de Cachoeira do Campo (1915), localidade próxima a Ouro Preto - região central. Ambas as escolas, antes de serem fechadas, passaram para o Gover $\neg$ no do Estado ou para o Federal, num momento seguinte (CAPDEVILLE, 1991:78-85).

Apesar de todas essas iniciativas, apenas a Escola Superior de Agri cultura deViçosa (ESAV), criada em 1926 pelo governo estadual, com o apoio das elites da Zona da Mata, ganhou legitimidade como centro de ciência (GOMIDE, 1995). Em recente pesquisa (OLIVER, 2005:144), pude compreender que a ESAV foi assumindo o papel de pólo de disseminação de pesquisas modernas para Minas Gerais, bem como de suas ideologias (AZEVEDO, 2006). Durante as décadas de 1930 e 1940, aquela escola responderia em grande parte pelo atendimento das de mandas científicas, provenientes diretamente dos agricultores e da Secretaria de Agricultura.

Nas páginas da Revista Agrícola e Comercial de Minas Gerais, um órgão da Sociedade Mineira de Agricultura, há uma grande participação dos órgãos e de agrônomos do governo federal em relação ao fomento da agricultura científica em Minas Gerais, nas décadas de 1930 e 1940. Nesse caso, devemos considerar que, possivelmente, o Governo Federal atuou junto ao Estadual também no episódio do mosaico, levando em considera- 
ção os diferentes interesses das elites regionais com aquelas esferas de poder.

Para Coelho (1992), foi pouca a participação da ESAV nos proble mas da agroindústria canavieira mineira, se comparada a outras cultu $\neg$ ras. No episódio do mosaico, essa participação ficou restrita às seguin $\neg$ tes medidas:

(... ) seleção de variedades resistentes entre as já existentes, processos de adubação e identificação de pragas (...) por se tratar de um produto de cultivo de longa data na região (e/ou país), suas pesquisas reduziram aqueles aspectos, sem demonstrar nos registros a intenção de construção de algo novo, mas, sim de aprimoramento do existente (COELHO, 1992:80).

No trecho acima, noto que a autora apresenta o mesmo tipo de expectativa que Shikida (1992), incluindo a falta de criação de algo novo ao caráter regional e temporário,já apontados anteriormente. Mesmo assim, identificou a precocidade dos trabalhos realizados sobre a canade-açúcar e, posteriormente, a elaboração de alguns estudos específicos para as condições mineiras desta cultura.

Assim, a autora evidencia que, no ano seguinte à criação da escola, em 1927, já havia cultivos para reproduzir a cana POJ 213. Para o diretor da escola, Peter Henry Rolfs, era importante, inclusive, usar variedades de cana resistentes ou livres de mosaico, como pastagem para a pecuária (COELHO, 1992:78). Desse interesse resultou um ar tigo sobre a viabilidade de canas javanesas como forragens ou pastagem, no Boletim de Agricultura, Zootecnia e Veterinária de Minas Gerais, em 1928, uma publicação da Secretaria de Agricultura de Minas Gerais. Dez anos depois, quandojá tinham feito experimentações com adubos, outros estudos foram publicados na Revista Ceres, revista científica e técnica da ESAV, sobre o uso da cana como forragens e sobre a fabri $\neg$ cação da rapadura.

A preocupação em adaptar e difundir canas javanesas próprias para a forragem ou pastagem e para a fabricação de rapadura indica que a ESAV estava ciente das transformações que ocorriam no setor cafeeiro e no canavieiro. A pesquisa assim realizada estava atenta à perda de for $\neg$ ça do pequeno produtor de rapadura, em face do crescimento das usinas ou da preferência pela pecuária, como alternativa ao café. 
É importante destacar que as pesquisas com as canas javanesas tiveram inicio primeiramente na ESAV. Legitimada politicamente como centro de ciência pelos agricultores da Zona da Mata, um quarto de sua clien $\neg$ tela era proveniente desta região, notadamente filhos de agricultores e fazendeiros (OLIVER, 2005:134). Nota-se que as principais usinas en contravam-se próximas à ESAV, nas quais alunos e professores mantinham constante contato, como veremos mais adiante.

Paralelamente, em 1929, no Boletim de Agricultura, Zootecnia e Veterinária de Minas Gerais (Ano II, n. 4, abril), o Diretor da Agricultura - Erᄀ nesto Von Sperling - divulgava uma nota sobre a distribuição de mudas de cana de Java. Os pedidos deveriam ser enviados ao Horto Florestal, em Belo Horizonte, da Secretaria da Agricultura. Para tanto, os agricultores fariam um registro de suas atividades agrícolas e paga $\neg$ riam quarenta réis pelo quilograma de mudas de javanesas (POJ 213 e 234), podendo, no máximo, comprar uma tonelada e, por oitenta réis, a variedade POJ 2725, sendo permitido adquirir, no máximo, cem quilogramas. Aqueles que não se registrassem também poderiam comprá-las, pagando cinqüenta réis e cem réis, respectivamente, pela quantidade mínima para os dois grupos de variedades. Já nos meses seguintes, a Secretaria de Agricultura de Minas Gerais divulgava que havia analisado as canas cultivadas em Ponte Nova e no Horto Flo $\neg$ restal de Belo Horizonte. O responsável por tais análises era o Dr. G. L. Tumang, químico da usina Ana Florência (BOLETIM DE AGRICULTURA, ZOOTECNIA E VETERINÁRIA DE MINAS GERAIS, ano II, $n^{\circ 5} 7$ e 8, julho e agosto de 1929:64).

Nesses anúncios oficiais, chama a atenção o fato de as canas terem sido vendidas e vinculadas à necessidade de um registro dos agricultores mineiros. Tal forma de disseminar a nova tecnologia reforça o discurso oficial sobre a necessidade de organizar e ter controle sobre a atividade agrícola mineira por parte do Estado. Assim, os esforços não ficariam apenas nas ações do Governo Federal e seus inspetores agrícolas. Esses dados também reforçam uma das assertivas levantadas por Shikida (1992) sobre a falta de organização política do setor, na época. E, ao mesmo tempo, indicam que as elites do setor canavieiro buscaram o Estado mineiro para solucionar a crise.

Em São Paulo, as variedades foram distribuídas gratuitamente. Essa possibilidade abre espaço para notarmos a classe dos usineiros como 
legítima fração burguesa da sociedade paulista, que ansiava do poder público - o Estado - o atendimento de suas demandas (QUEDA, 1972). Na interpretação de Fernando Azevedo (1948), o usineiro era um típi $\neg$ co burguês, símbolo das forças modernas que dominavam as forças naturais através das máquinas e da ciência. Segundo Gnaccarini (1972), essa dominação também se deu por meio de uma série de mecanismos econômicos para regular o mercado a seu favor.

Quanto às variedades preconizadas e comercializadas em Minas Gerais, a POJ 213 e a POJ 234 eram as mesmas que mais foram dissemiᄀ nadas em São Paulo, sendo estas variedades apenas resistentes ao mosaico e não imunes (OLIVER, 2001). A variedade POJ 2725 tinha sido im? portada para Minas Gerais, diretamente da Argentina, pela Diretoria da Agricultura. Tinham a expectativa de atender à produção industrial, da mesma forma que em São Paulo, pertencendo ao terceiro estágio de difu $\neg$ são tecnológica.

O fato de profissionais das usinas terem participado das análises científicas de interesse para a Secretaria da Agricultura de Minas Gerais indica que o poder público buscou utilizar uma infra-estrutura de ciên $\neg$ cia e tecnologia já instalada dentro das próprias usinas. Esse seria o principal fator distintivo das políticas voltadas para a debelação do mo saico entre São Paulo e Minas Gerais.

Na leitura dos relatórios do Departamento de Fitopatologia da ESAV, essa postura se confirma, quando notificaram as visitas feitas às Usinas Rio Branco e Ana Florência, desde 1932 até 1949. Para este artigo, destaco o relatório de Fitopatologia de 1932, no qual encontramos as se guintes considerações sobre o mosaico:

É esta a moléstia que presentemente mais exige uma rigorosa campanha, e o exigirá ainda durante um decênio. O exemplo do Município de Viçosa é bastante para demonstrar como o mosaico tem aniquilado a lavoura de cana, em pequena escala. Pelos dados fornecidos pela Prefeitura vemos que, exportando 686 toneladas de rapadura em 1928, Viçosa desceu a exportar em 1930 , apenas 3 toneladas, devido ao abandono da lavoura de cana, quase exclusivamente em virtude do mosaico. Quanto a lavoura em grande escala, representada pelas Usinas de Rio Branco e Ana Florência, seus fornecedores vinham cada ano fornecendo menor tonelagem, até chegarem a situação de se verem ameaçados de extinção, tão baixa a tonelagem recebida, cada safra para moagem, em resultado do mosaico (fl. 180) (grifos meus). 
Na seqüência, comenta que o processo de substituição de variedades era recente e passou antes pelo de determinação de qual variedade javanesa era mais apropriada para a lavoura mineira. Após essas etapas, o fitopatologista Albert Stanley Müller, da ESAV, registra que o "fracasso das canas velhas dos fornecedores" não afetava mais a produção das usinas, que atingiram safra recorde, também em virtude do aumento de seus próprios terrenos.

Da mesma forma, comentava que as usinas fizeram grandes esforços em difundir as canas javanesas entre seus fornecedores e outros plantado $\neg$ res. Além disso, salientou os trabalhos do "Sr. Rochebais na Usina Rio Branco, cujo fim é separar tipos (da cana C.B. 3100 - criação da Estação Experimental de Campos/RJ do Ministério da Agricultura) resistentes ao mosaico e distintas morfologicamente" (fl. 180), sugerindo que o apren dizado sobre a nova tecnologia ocorreu dentro daquelas usinas, voltandose, inclusive, para a experimentação continuada de novas variedades.

Segundo dados do Anuário Assucareiro de 1942, as duas usinas citadas acima eram também as de maior capacidade produtiva durante toda a década de 1930. Nas safras de 1937 a 1939, representaram a metade da produção de açúcar de usina de Minas Gerais, uma participação que tendeu a diminuir a partir de 1940 , com o surgimento de novas usinas. Assim, a presença de uma infra-estrutura técnico-científica, dentro e fora das usinas, em paralelo ao crescimento da produção de açúcar de usina e com certo apoio político (Estadual e/ou Federal) indicaria a presença de um processo de modernização tecnológica em curso. E, da mesma forma que no caso paulista, esse processo estaria integrado aos fatores estruturais e conjunturais próprios da agroindústria canavieira de Minas Gerais.

\section{Conclusões}

Desde 1926, José Vizioli destacara em seu plano a criação de uma Estação Experimental, o que não foi tomado como meta no plano nacional de defesa da cana. Por outro lado, a constituição dessa infraestrutura em São Paulo não se deu de forma simples e linear. Como vimos, o plano de José Vizioli esteve muitas vezes ameaçado em razão de disputas políticas, dificultando sua adoção como política oficial do Governo paulista. 
Teve grande influência na criação da Estação Experimental o apoio da ESALQ. A receptividade dessa escola parece estar em conformidade com o momento de consolidação de seu projeto de ensino (MENDON ᄀ ÇA, 1998). Além disso, outras transformações estavam em curso, em que a ESALQ se consolidaria como uma instituição também de pesquisa (OLIVER, 2005). Sobre isso, a ESAV nada deixaria a desejar. Entretanto, no momento das medidas de debelação do mosaico, aquela instituição ainda não apresentava uma relação consolidada com o meio produtivo, quer fosse pela formação de filhos de fazendeiros ou pelo ingresso de ex-alunos nos quadros do Estado de Minas Gerais, o que passou a ocor $\neg$ rer apenas no início dos anos 1950 (CAPDEVILLE, 1979). Em São Paulo, isso já ocorria desde o início da década de 1930 e, principalmente, no decorrer da década de 1940 (OLIVER, 2005:136).

Em virtude do mosaico, uma estação experimental também era necessária para ampliar a área de multiplicação das mudas e para a subs $\neg$ tituição e a seleção constante de novas variedades. Novas substituições deveriam ocorrer para trazer maior resistência ao mosaico e aumentar o volume de cana cortada por hectare e de teor de açúcar por hectare. A estação experimental era o lugar mundialmente conhecido para que esse aprendizado técnico-científico tomasse forma e tivesse início uma relação com os produtores. Mas, no caso mineiro, isso ocorreu dentro das próprias usinas. A necessidade de proximidade das pesquisas com o setor produtivo na EECP resultou em trabalhos de cooperação com as maiores usinas paulistas. Esses campos de cooperação tinham como objetivo realizar ensaios de competição entre variedades dentro das usinas.

Segundo Hayami \& Ruttan (1988:244), a pesquisa científica e tecnológica agrícola nos Estados Unidos foi financiada prioritariamente por recursos públicos estaduais e, em segundo plano, por recursos fede $\neg$ rais e privados, no decorrer da segunda guerra mundial e posteriormente a ela. Assim, o caso mineiro fugiria drasticamente ao modelo tradicional. Os autores acima ainda fizeram notar que as instituições de pesquisa agrícola (escolas agrícolas, laboratórios e Estações Experimentais) foram muito mais efetivas em desenvolver conhecimentos tecnológicos, base ados na nascente biologia e na química, do que na geração de tecnolo $\neg$ gias mecânicas que ficariam para a iniciativa privada (HAYAMI \& RUTTAN, 1988:246-247). 
Nestas áreas, não privilegiadas pelas instituições de ciências agrícolas, sabemos que a institucionalização da P\&D nas empresas garantiu seu crescimento e sua manutenção como as maiores do mercado (MOWERY \& ROSENBERG, 2005:28). No caso da agroindústria canavieira paulis $\neg$ ta, os grupos formados a partir da década de 1930 apresentavam como característica comum o investimento em tecnologia própria ou em parcerias com a Estação Experimental (OLIVER, 2001; OLIVER \& SZMRECSÁNYI, 2003). Na ausência de um apoio público continuado à criação de diversas instituições científicas em Minas Gerais, tal como havia ocorrido em São Paulo (SZMRECSÁNYI, 1996), nada impedia que a iniciativa particular tivesse ganhado destaque, quer fosse na agri cultura, quer fosse em outros setores.

Entretanto, numa perspectiva histórica da tecnologia agrícola, o caso mineiro, apesar de excepcional, não seria em si uma prova de que as medidas não tivessem sido efetivas em relação a um processo de mo dernização tecnológica na agroindústria canavieira de Minas Gerais. Ao contrário, as iniciativas particulares, orientadas por especialistas, teriam encurtado o tempo do processo de adaptação da nova tecnologia às condições locais das usinas mineiras. Assim, a inexistência de uma Esta ção Experimental de cana-de-açúcar em Minas Gerais não pode ser tomada como mais um fato que diferencia as duas regiões.

Portanto, trajetórias históricas distintas de aporte às ciências agríco $\neg$ las não impediram que uma nova tecnologia fosse incorporada à pro $\neg$ dução em ambos os casos. De acordo com o que foi exposto, o mosai co da cana-de-açúcar em Minas Gerais não propiciou a criação de uma estação experimental, porque o ambiente institucional mineiro para as ciências agrícolas se encontrava em formação e com tendência a se centralizar na ESAV. No mesmo momento, as grandes usinas atuavam de forma independente, tendo na prática dos técnicos o lugar do apren dizado sobre a tecnologia.

Porém, é possível compreender que as usinas paulistas dividiram os custos das pesquisas agrícolas ou mesmo relegaram ao Estado esse ônus. Isto possibilitou a criação de um único centro de referência científica e de experimentação, que estava em diálogo com os demais centros internacionais, constituindo-se também como mais um centro de orga $\neg$ nização política frente ao IAA. Para tanto, passou a divulgar a necessiᄀ dade de reversão do excesso de açúcar em álcool combustível e a dis- 
tribuir fermentos selecionados. E, novamente, José Vizioli esteve à frente dessa bandeira no Estado e no Governo Federal.

No caso mineiro, a independência da capacitação técnico-científica pode ter propiciado tanto uma concorrência entre usinas como o dis ᄀ tanciamento da rede internacional de difusão de tecnologia. Possivel $\neg$ mente, face ao contexto econômico de quotas de produção, essas iniᄀ ciativas teriam ficado enfraquecidas politicamente, tanto pela ausência de um centro científico que atendesse também às demandas políticas quanto pelos interesses econômicos da classe dos usineiros.

\section{Referências bibliográficas}

ALbUQUERQUe, Rui; ORTEGA, Antônio e REYDON, Baastian, "O setor Público de Pesquisa Agrícola no Estado de São Paulo", Parte II, Cadernos de Difusão Tecnológica, 3(2), maio-ago., 1986:243-296.

AZEVEDo, Denílson, "Melhoramento do homem, do animal e da semente: o projeto político-pedagógico da ESAV do Estado de Minas Gerais (1920-1948), organização e funcionamento". Universidade de São Paulo, São Paulo, Tese de Doutorado, 2005.

AZEVEDO, Fernando, Canaviais e Engenhos na vida política do Brasil: ensaio sociológico sobre o elemento político na civilização do açúcar, Rio de Janeiro: IAA, 1948.

B YE, Pascal; MEUNIER, Ariel e Muchnik, José, " As inovações açucareiras: permanência e diversidade de paradigmas". Cadernos de Ciência \& Tecnologia, Brasília, 10(1/3), 1993:35-52.

CAPDEVILlE, Guy, "A percepção dos engenheiros agrônomos, sobre a adequação de sua formação às exigências do mercado de trabalho, em três estados brasileiros". Rio de Janeiro/DE/PUC/RJ, Dissertação de Mestrado, 1979. O ensino superior agrícola no Brasil. Viçosa: Ed. UFV, 1991.

C A R R A R A, Ângelo, Estruturas agrárias e capitalismo: contribuição para o estudo da ocu pação do Solo e daTransformação do trabalho na Zona da Mata Mineira (séculos XVIII e XIX). Série Estudos, n² 2, Mariana: UFOP, 1999.

COELHO, France, "A produção científico-tecnológica para agropecuária: da ESSAV à UREMEG, conteúdos e significados". Viçosa/DER/UFV, Dissertação de Mesᄀ trado, 1992 .

EISEMBERG, Peter, Modernização sem Mudança: a indústria canavieira em Pernambuco, 1840-1910. Rio de Janeiro: Paz \& Terra, 1977.

EVENSON, Robert, "International Diffusion of Agrarian Technology". Journal of Economic History, XXXIV, 1, mar., 1974:51-73.

, "International Transmission of TechnologyintheProduction of Sugarcane". Journal of Development Studies, 12(2), jan., 1976:208-231. 
FIGUEIRôA, Silvia, As Ciências Geológicas no Brasil: Uma História Social e Institucional, 1875-1934. São Paulo: Hucitec, 1997.

FIGUEIRÔA, Silvia. \& LOPES, Maria," A difusão da ciência e da tecnologia através da imprensa e dos periódicos especializados: 1890-1930". Anais dos VI Seminário Nacional de História da Ciência e da Tecnologia, S B HC. R i o de Janeiro, 1997:190-194.

G N A C C A R I N I, José, "Estado, Ideologia e Ação Empresarial na agroindústria açucareira de São Paulo". São Paulo, FFLCH/U S P, Tese de Doutorado, 1972 .

G O D Y Marcelo, "No país das minas de ouro a paisagem vertia engenhos de cana e casas de negócio - Um estudo das atividades agroaçucareiras tradicionais mineiras, entre o Setecentos e o Novecentos, e do complexo mercantil da província de Mi nas Gerais". São Paulo: FFLCH/USP, Tese de Doutorado, 2004.

, "Persistência do tradicional: o processo de modernização da agroindústria canavieira do Brasil e a sobrevivência de formas produtivas não-capitalistas". Texto para Discussão n. 309, Belo Horizonte/UFMG/CEDEPLAR, 2007, 24 pp.

GOMES, Maria, "Mapas e mapeamentos: dimensões históricas; as políticas cartográficas em Minas Gerais (1850-1930), Tese de Doutorado, FAFICH/UFMG, 2005.

G O M IDE, Marilda, " O ideário rural no Brasil 1930-1940: Entre a Tradição e a Moder nidade". UF V, Dissertação de Mestrado, 1995.

G R A Z I A N O D A SILVA, José, Progresso técnico e relações de trabalho na agricultura. São Pau lo: Hucitec, 1980 .

H A Y A M I, Y. e R U T T A N, V., Desenvolvimento agrícola: teoria e experiências internacionais. Brasília: E M B R A P A, 1988 .

LAFUENTE, Antonio e ORTEGA, María L., "Modelos de mundialización de la ciencia", Arbor, CXLII, 558-559-560,jun.-ago., 1992:93-117.

M A S S A R A N I, Luisa e Moreira, Ildeu, " A divulgação científica no Rio de Janeiro: Algumas reflexões sobre a década de 1920", História, ciência, saúde: Manguinhos.V. 7, n. 2, $2000: 627-651$.

MELoni, Reginaldo. "Ciência e Produção Agrícola. A Imperial Estação Agronômica de Campinas - 1887-1897". São Paulo: FFLCH-USP, Dissertação de Mestrado, 1999.

M E N D O N ÇA, Sonia, $O$ ruralismo brasileiro. São Paulo: Hucitec, 1990.

Agronomia e Poder no Brasil. Ri o de Janeiro: Vício de Leitura, 1998.

M OWERY, David e ROSENBERG, Nathan, Trajetórias da inovação: A mudança tecnoló gica nos Estados Unidos da América no século XX. Campinas: Unicamp, 2005.

OLIVER, Graciela, "José Vizioli e o início da modernização tecnológica da agroindústria canavieira paulista, 1919-1949". Campinas: D PCT/IG/UN I CAMP, Dissertação de Mestrado, 2001 .

, "O papel das escolas superiores de agricultura na institucionalização das ciên cias agrícolas, 1930 e 1950 : práticas acadêmicas, currículos e formação profissional". Campinas: IG/UNICAMP, Tese de Doutorado, 2005.

OLIVER, Graciela e SZMRECSÁNYI, Tamás, "A Estação Experimental de Piracicaba e a modernização tecnológica da agroindústria canavieira (1920 a 1940)". Revista Brasileira de História. São Paulo, v. 23(46), 2003:37-60. 
OLIVER, Graciela e FIGUEIRÔA, Silvia, "Características da institucionalização das ciências agrícolas no Brasil". Revista da Sociedade Brasileira de História da Ciência, v. 4,ju1.-dez., 2006:104-114.

QUEDA, Oriowaldo, "A Intervenção do Estado e a Agroindústria Açucareira Paulista". Piracicaba: ESALQ/USP, Tese de Doutorado, 1972.

. "A importânciae os impactos da debelaçãodo mosaicoeocrescimentoda lavoura canavieira no Estado de São Paulo (1923-1940)", Simpósio Los complejos Azucareros en la Argentina y Brasil: aspectos sociales y politicos, 1890-1945, nas XVI Jor ר nadas de Historia Económica, Quilmes, 16-18 de setembro de 1998 (mimeo.).

RAMOS, Pedro, Agroindústria Canavieira e Propriedade Fundiária no Brasil. São Paulo: Ed. Hucitec, 1999.

RAMOS, Pedro e SZMRECSÁNYI, Tamás, "Evolução histórica dos grupos empresariais da agroindústria canavieira paulista". História Econômica \& História de Empresas, v. 1, 2002:85-115.

RIBEIRO, Áureo, "A economia do varejo: agricultura, governo e mercados locais no nordeste de Minas Gerais no começo do século XX". Anais do IX Seminário sobre economia mineira. Belo Horizonte, 2000:179-210.

SALDAÑA, Juan, "Ciência e Identidade Cultural: A História da Ciência na América Latina". Um olhar sobre o passado. História das Ciências na América Latina. Campinas: Editora da UNICAMP/São Paulo: Imprensa Oficial, 2000:11-32.

SHIKIDA, Pery, " A evolução da agroindústria canavieira de Minas Gerais, 1705-1955". Dissertação de Mestrado. Piracicaba, ESALQ, 1992.

SHIKIDA, Pery e BACHA, Carlos, "Mudanças Tecnológicas e evolução da agroindús ᄀ tria canavieira de Minas Gerais e São Paulo (1885-1933)", Tempo da Ciência, 4(7), 1997:15-28.

SILVA, André, A campanha contra a broca-do-café em São Paulo. História, Ciências, Saúde-Manguinhos, v. 13, 2006:957-993.

SZMERECSÁNYI, Tamás, "Origens da liderança científica e tecnológica paulista no século X X". Textos para discussão, Campinas, SP: DPCT/IG/UNCAMP, n. 15, 1996.

"Crescimentoe crise da agroindústria açucareira do Brasil, 1914-1939". Re 7 vista Brasileira de Ciências Sociais. V. 7, n. 5, jun., 1988:32-68.

. "Agrarianbourgeoisie, regionalgovernmentand theorigins of SãoPaulo's modern sugar industry, 1870-1930". Cadernos do Instituto de Geociências. Campinas: IG/UNICAMP, v. 2, n. 1, 1992:125-135.

VEIGA FILHO, Alceu e SANTOS, Zuleima, "Padrão Tecnológico da cana-de-açúcar no Estado de São Paulo: evidências empíricas da evolução na cultura". Informações Econômicas. São Paulo, 25(8), ago., 1995:15-24.

VISCARDI, Cláudia, "Elites Políticas em Minas Gerais na Primeira República". Revista de Estudos Históricos. V. 8, n. 15, R i o de Janeiro, 1995:39-56.

, Resenhadolivrode Jorge Ferreira e Lucilia de Almeida N. Delgado (org.). "O Brasil Republicano". Revista Brasileira de História. V. 25, n. 50,ju1.-dez, 2005:337-341. 


\section{Documentos citados}

Antigo Arquivo Histórico Central da Universidade Federal de Viçosa

Relatório de Fitopatologia de Albert Stanley Müller, ESAV, 1932

\section{Arquivo Público Mineiro - Belo Horizonte/MG}

GORCEIX, Henri, O ensino Agrícola em Minas Gerais. Relatório apresentado ao Dr. Secretá rio de Estado da Agricultura. Ouro Preto: Imprensa Oficial, 1897.

\section{Biblioteca Central da Universidade Federal de Viçosa}

Revista Ceres, 1938

\section{Biblioteca da Estação Experimental de Tucumã - Argentina}

CROSS, William. "E1 mosaico de la cana de azucar", Circular n. 10 de la Estación Experi mental Agrícola de Tucumán, 1929.

Biblioteca da Faculdade de Ciências Econômicas da UFMG

Anuário Assucareiro de 1942

Boletim de Agricultura, Zootecnia e Veterinária de Minas Gerais, 1928 e 1929

Revista Agrícola e Comercial de Minas Gerais, década de 1930

Biblioteca de Agricultura (Bianagri) - Ministério da Agricultura/Brasília

EStado De PERnAmbuCO, Regulamento do Serviço de Combate ao Mosaico da Canade-Açúcar, Recife: Imprensa Oficial, 1927:1-9.

\section{Biblioteca do Instituto Agronômico de Campinas - SP}

SECRETARIA DA AGRICULTURA Indústria E COMÉRCIO, Relatório da Secretaria da Agricultura apresentado ao Dr. Carlos Campos pelo Gabriel Ribeiro dos Santos ano de 1925. São Paulo: Imprensa Oficial, 1926.

SECRETARIA DA AGRICULTURA INDÚSTRIA E COMÉRCIO, Relatório apresentado ao Dr. Carlos Campos por Gabriel Ribeiro dos Santos, Secretário da Agricultura, ano de 1926. São Paulo: Imprensa Oficial, 1927.

SECRETARIA DA AGRICULTURA INDÚSTRIA E COMÉRCIO, Reorganização dos seus serviços de dezembro de 1930 a junho de 1931, sendo o interventor federal no Estado de São Paulo o Coronel João Alberto Lins de Barros e Secretário da Agricultura o Dr. Edmundo Navarro de Andrade. São Paulo: Imprensa Oficial, 1931.

VIZIOLI, José, "Nos canaviais do Estado os danos causados pelas pragas e moléstias nas culturas". Boletim da Agricultura, 1924:455-462.

"A presente situação da indústria açucareira no Estado de São Paulo". Boletim da Agricultura, 1926:320-321; 388-398; 399-423. 
VIZIoLI, José, "A indústria açucareira na República Argentina". Separata do Boletim da Agricultura, 1927.

\section{Biblioteca do Instituto Biológico - São Paulo/SP}

BITANCOURT, Agesilau, "Mosaico e doenças das riscas - Streak disease", Revista Agrí cola, 1(1), nov.-dez., 1926. 